\title{
The impact of rotational speed and water volume on textile translational motion in a front loading washer
}

DOI:

$10.1177 / 0040517518809042$

\section{Document Version}

Accepted author manuscript

Link to publication record in Manchester Research Explorer

\section{Citation for published version (APA):}

Hong, L., Gong, R., Xu, P., Ding, X., \& Wu, X. (2018). The impact of rotational speed and water volume on textile translational motion in a front loading washer. Textile Research Journal.

https://doi.org/10.1177/0040517518809042

\section{Published in:}

Textile Research Journal

\section{Citing this paper}

Please note that where the full-text provided on Manchester Research Explorer is the Author Accepted Manuscript or Proof version this may differ from the final Published version. If citing, it is advised that you check and use the publisher's definitive version.

\section{General rights}

Copyright and moral rights for the publications made accessible in the Research Explorer are retained by the authors and/or other copyright owners and it is a condition of accessing publications that users recognise and abide by the legal requirements associated with these rights.

\section{Takedown policy}

If you believe that this document breaches copyright please refer to the University of Manchester's Takedown Procedures [http://man.ac.uk/04Y6Bo] or contact uml.scholarlycommunications@manchester.ac.uk providing relevant details, so we can investigate your claim.

\section{OPEN ACCESS}


The impact of rotational speed and water volume on textile translational motion in a front loading washer

Hong $\mathrm{Liu}^{1}$, R, Hugh Gong ${ }^{2}$, Pinghua $\mathrm{Xu}^{3}$, Xuemei Ding ${ }^{1,4}$, Xiongying $\mathrm{Wu}^{1,5}$

${ }^{1}$ Fashion Institute, Donghua University, Shanghai 200051, China

${ }^{2}$ Textiles, School of Materials, University of Manchester, Manchester M13 9PL, UK

${ }^{3}$ Fashion School \& Engineering, Zhengjiang SCI-TECH University, 310018, China

${ }^{4}$ Key Laboratory of Clothing Design \& Technology (Donghua University), Ministry of Education, Shanghai 200051, China

${ }^{5}$ Shanghai Entry-Exit Inspection and Quarantine Bureau, 200134, China

*Corresponding author. Tel.: (86)15821882692

Postal address: No.1882 West Yan’an Road, Shanghai, China

E-mail addresses: fddingxm@dhu.edu.cn

\begin{abstract}
Textile motion in a front loading washer has been characterized via video capturing, and processing system developed based on image geometric moment. Textile motion significantly contributes to the mass transfer of wash solution in porous materials, particularly in the radial direction (perpendicular to the rotational axis of the inner drum). In this paper, the velocity profile and residence time distribution of tracer textile have been investigated to characterize the textile dynamics in the front loading washer. The results show that the textile motion varies significantly with the water volume and rotational speed, and the motion path follows certain patterns. Two regions are observed in the velocity plots: a passive region where the textile moves up with low velocity and an active region where the textile falls down with relatively high speed. A stagnant area in the residence time profile is observed. This corresponds to the passive region in the velocity profile. The stagnant area affects the mechanical action, thus influences washing efficiency and textile performance. The findings on textile dynamics will help in the development of better front loading washers.
\end{abstract}

Key words: mass transfer, textile motion, velocity profiles, washing machine

\title{
1. Introduction
}


In a drum washer, the cleaning process is a soil transfer process involving large deformation of clothes and three-dimensional motion of cloth and fluid. However, the modern drum washer is typically seen as a 'black box', the design and optimization of the washer is usually through full-scale trials rather than the theoretical understanding of the textile and fluid dynamics. The optimization is often less than ideal, leading to washer designs that cause resource waste and environment pollution ${ }^{1}$. Inadequate understanding of the process can lead to soil deposition and textile deformation ${ }^{2-4}$. The rotation of the inner drum during washing is to enhance the mass transfer within the textiles ${ }^{5}$. The inner drum rotation can be alternated between clockwise and anti-clockwise directions to increase the interaction of fluids and textiles, resulting in soil loosening from textiles. Therefore, it is important to study the mechanics of textile rotating with the inner drum.

A great number of recent studies focus on factors affecting mass transfer in porous soft materials. The common factors include agitator speed, cloth/liquor ratio, hydrodynamic flow, textile porosity, temperature, stroke angle, initial placement and concentration of detergent. ${ }^{6-13}$ Several mathematical models of the washing process have been developed for both top-loading and front-loading washers. ${ }^{14-16}$ However, accurate information about the soft porous material properties (porosity, stiffness, etc.), dynamic viscosity of the mixture and textile/liquid flow patterns is required for modeling. These parameters cannot be seen as constants due to the dynamic nature of the washing process. ${ }^{17}$ Therefore, many of these models were established based on oversimplified assumptions ${ }^{18 \text {, }}$ ${ }^{19}$ due to the lack of information about the interaction of the fluid and fabrics and the properties of wet textiles. Textile dynamics in a front loading washer is not only influenced by the wash load, but also the rotational speed and water volume. Hence, to develop an optimized washer, it is necessary to study the effect of rotational speed and water volume on the textile dynamics including the textile velocities and the residence time distribution ${ }^{17,20,21}$.

Many researchers have focused on factors influencing the textile flow pattern and wash performance such as washing efficiency, wrinkling and shrinkage. ${ }^{22-29}$ For example, a high-speed camera was used to record the fabric movement and the outlines of the motion textile were recorded for data analysis. $^{30-32}$ The textile motion was classified into four patterns: sliding, falling, rotating and centrifugal. Complex motion patterns including sliding, falling and rotating led to higher washing efficiency and more severe abrasion of textile. However, it is not clear how the textile motion was tracked. Mac Namara ${ }^{11,17}$ used the technique of positron emission particle tracking (PEPT) to 
investigate the textile dynamics in a front loading washer for different washing load sizes, but the experiments had to be performed in a special environment due to radioactivity.

In this study, we developed a new and more practical method to record textile motion based on image geometric moments. We investigated the effect of washing rotational speed and the water volume on the velocity distribution and residence time of textiles. The information obtained deepens the understanding of the mechanism of textile motion and provides guidance in the optimization of washing parameters for front loading washers.

\section{Experimental methods and materials}

\subsection{Recording the fabric movements}

In order to analyze the fabric movement, a video capturing and processing system was developed. This system consists of three parts: the video capturing rig, image processing system, and input and output system. The video capturing rig is a high speed camera GoProHERO 5 at a speed of 120 frames per sec.

In the experiments, a tracer textile with a specific color (yellow) was used. The image of the textile captured by the high speed camera is a RGB color image. The RGB image depends on the reflected light which is affected by the lightness ${ }^{33}, 34$. This image is not appropriate for further processing. The HSV (hue saturation value) color space describes perceptual color relationships more accurately than the RGB color space, and it is computationally simple. The HSV color space enables the identification of specific colors more easily by hue. Thus, we convert the captured RGB image into the HSV space. The HSV image is then converted into binary image by segmentation with a threshold. As the tracer textile is yellow, the corresponding threshold range in hue is between 30 to 50. Finally, the mass centroid of the connected region of the tracked textile is calculated based on geometric moments using Eq. (1) and (2) ${ }^{35}$ :

$$
\begin{aligned}
& m_{i j}=\sum_{x, y}\left(I(x, y) \cdot x^{i} \cdot y^{j}\right) \\
& u_{i j}=\sum_{x, y}\left(I(x, y) \cdot(x-\bar{x})^{j} \cdot(y-\bar{y})^{j}\right)
\end{aligned}
$$

Where, $m_{i j}$ is the raw moment of a raster image; $I(x, y)$ is the pixel intensity of image; $u_{i j}$ is the central moment of image; $\bar{x}$ and $\bar{y}$ is the center of gravity of the binary image.

Using binary images the gray value function $I(x, y)$ becomes:

$$
I(x, y)=\left\{\begin{array}{lr}
1 & \text { Object } \\
0 & \text { Background }
\end{array}\right.
$$


The coordinates $\bar{x}$ and $\bar{y}$ of the center of gravity of the binary image are simply calculated by the raw moments of first order $m_{10}$ and $m_{01}$ divided by the zero order moment $m_{00}$, using expression:

$$
\begin{aligned}
& \bar{x}=\frac{m_{10}}{m_{00}} \\
& \bar{y}=\frac{m_{01}}{m_{00}}
\end{aligned}
$$

The centroid of tracer textile was calculated and the motion of the centroid was considered as the motion of the textile. No detergent was added during textile motion observation in order to reduce the impact of bubbles.

\subsection{Experimental details}

\section{Washer}

Experiments were carried out in a Haier WH7560P2 modified according to ISO7330:2012 with a capacity of $7 \mathrm{Kg}$. The diameter of the inner drum is $490 \mathrm{~mm}$ and the depth is $275 \mathrm{~mm}$. The drum rotational speed was set according to the adjustable range of the washing machine. The water volume was set based on the water level seen in the inner drum. The lowest water volume was set at $6 \mathrm{~L}$ when there is no free water in the inner drum; the highest water volume was set at $12 \mathrm{~L}$ when the textiles were just completely immersed in water.

\section{Specimens}

Cotton pillowcases were placed inside the machine to achieve $1 \mathrm{~kg}$ wash load, the detailed specifications of the pillowcases are show in Table 1. The detailed information of the experiments is shown in Table 2 and Table 3.

EMPA 106 soiled with carbon black and mineral oil was utilized to evaluate washing performance. A total of 10 EMPA 106 samples were included in each experiment. Two of the pillowcases were attached with five EMPA samples each. The IEC 60456 Reference Base Detergent Type A*(no phosphate) was used.

Table 1. Specifications of the textile samples

\begin{tabular}{cccc}
\hline Fiber content & Weave type & Size $(\mathrm{cm} \times \mathrm{cm})$ & Weight $(\mathrm{g} /$ piece $)$ \\
\hline $100 \%$ cotton & Plain & $50 \times 80( \pm 5)$ & $240 \pm 5$ \\
\hline
\end{tabular}




\begin{tabular}{cccccc}
\hline $\begin{array}{c}\text { Temperature } \\
\left({ }^{\circ} \mathrm{C}\right)\end{array}$ & Drum & Water & Washing & Rinsing & Rinsing \\
& $\begin{array}{c}\text { speed } \\
(\mathrm{rpm})\end{array}$ & $\begin{array}{c}\text { volume } \\
(\mathrm{L})\end{array}$ & $\begin{array}{c}\text { time } \\
(\mathrm{min})\end{array}$ & runs & $\begin{array}{c}\text { Time } \\
(\mathrm{min})\end{array}$ \\
\hline $30 \pm 2$ & $30 / 40 / 50 / 60$ & 8 & 30 & 2 & 3 \\
\hline
\end{tabular}

Table 3. Washing parameters with controlled water volume

\begin{tabular}{cccccc}
\hline $\begin{array}{c}\text { Temperature } \\
\left({ }^{\circ} \mathrm{C}\right)\end{array}$ & Drum & Water & Washing & Rinsing & Rinsing \\
& speed & volume & time & runs & Time \\
$(\mathrm{rpm})$ & $(\mathrm{L})$ & $(\mathrm{min})$ & & $(\mathrm{min})$ \\
\hline $30 \pm 2$ & 40 & $6 / 9 / 12$ & 30 & 2 & 3 \\
\hline
\end{tabular}

\subsection{Data analysis}

During each rotation period, the inner drum rotation can be alternated between clockwise and anti-clockwise directions lasting 25 seconds at a controlled rotational speed. Thus from each experiment, two data subsets were obtained, clockwise and anticlockwise tracer textile location respectively. The plots obtained from anti-clockwise and clockwise are almost symmetrical. In order to present all data obtained from one experiment, the clockwise data subset was horizontally flipped relative to the axis of rotation of the drum. Then the plots present anti-clockwise data and 'flipped' clockwise data.

Lagrangian velocity. Lagrangian velocities were calculated according to Mac Namara et al. ${ }^{17}$ and Bakalis et $\mathrm{al}^{36}$. A polynomial line was generated for a number of successive points as a function of time and the slop of the line at the midpoint of these data was taken as the Lagrangian velocity, $u_{i}$, as shown in Fig.1. The number of points ' $n$ ' used to polynomial was determined by minimizing the least squares error. For example, if there was a sudden direction change in the trajectory (Fig.1), fewer points would be more accurate. The detailed information and illustration of the velocity calculation can be found in the paper cited above. 


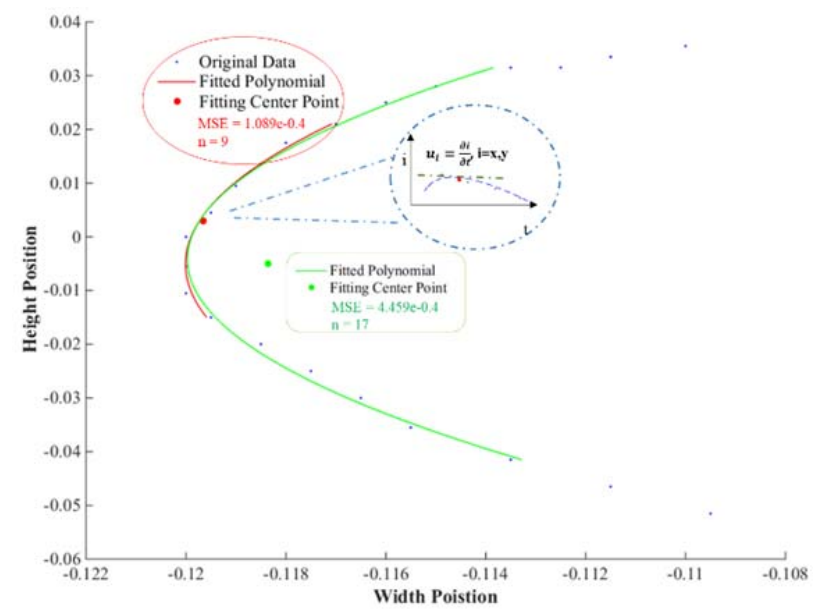

Figure 1. Trajectory of tracer textiles and calculation of Lagrangian velocity

Eulerian velocity. Eulerian velocities were represented graphically in a user-defined 2D cell grid and the loading area was divided into equal size cells. The Eulerian data was the time-weighted average throughout each respective cell, as shown in Fig.2. ${ }^{37}$ Lagrangian and Eulerian velocities depicted in this study are all non-dimensional ratios with reference to the maximum velocity been observed in the experiments.

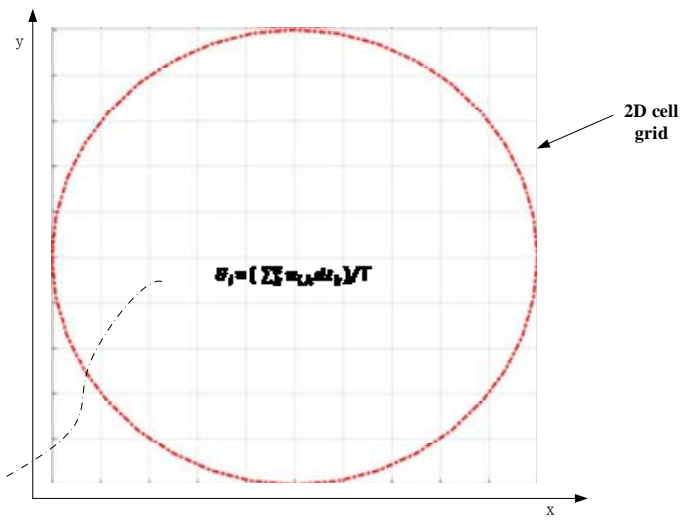

Figure2. 2D cell grid and calculation of Eulerian velocity

Residence time. Residence time plots represent the average time the tracer textiles stay in every cell been defined in Eulerian velocity calculation ${ }^{37}$. These values were calculated as the cumulative residence time divided by the number of passes.

\section{Results and discussion}

\subsection{Effect of rotational speed and water volume on textile speed distribution}

\subsubsection{Speed distributions for different rotational speed and water volume}

Fig. $3 \& 5$ present textile speed maps from the front of the washing machine for each experimental condition. The velocity of textile was calculated by combining the velocities $\mathrm{x}$ and $\mathrm{y}$ directions, as in 
Eq. (6),

$$
U_{\text {total }}=\sqrt{U_{x}^{2}+U_{y}^{2}}
$$

Where $U_{x}$ and $U_{y}$ are the centroid speeds in $\mathrm{x}$ and y directions respectively.

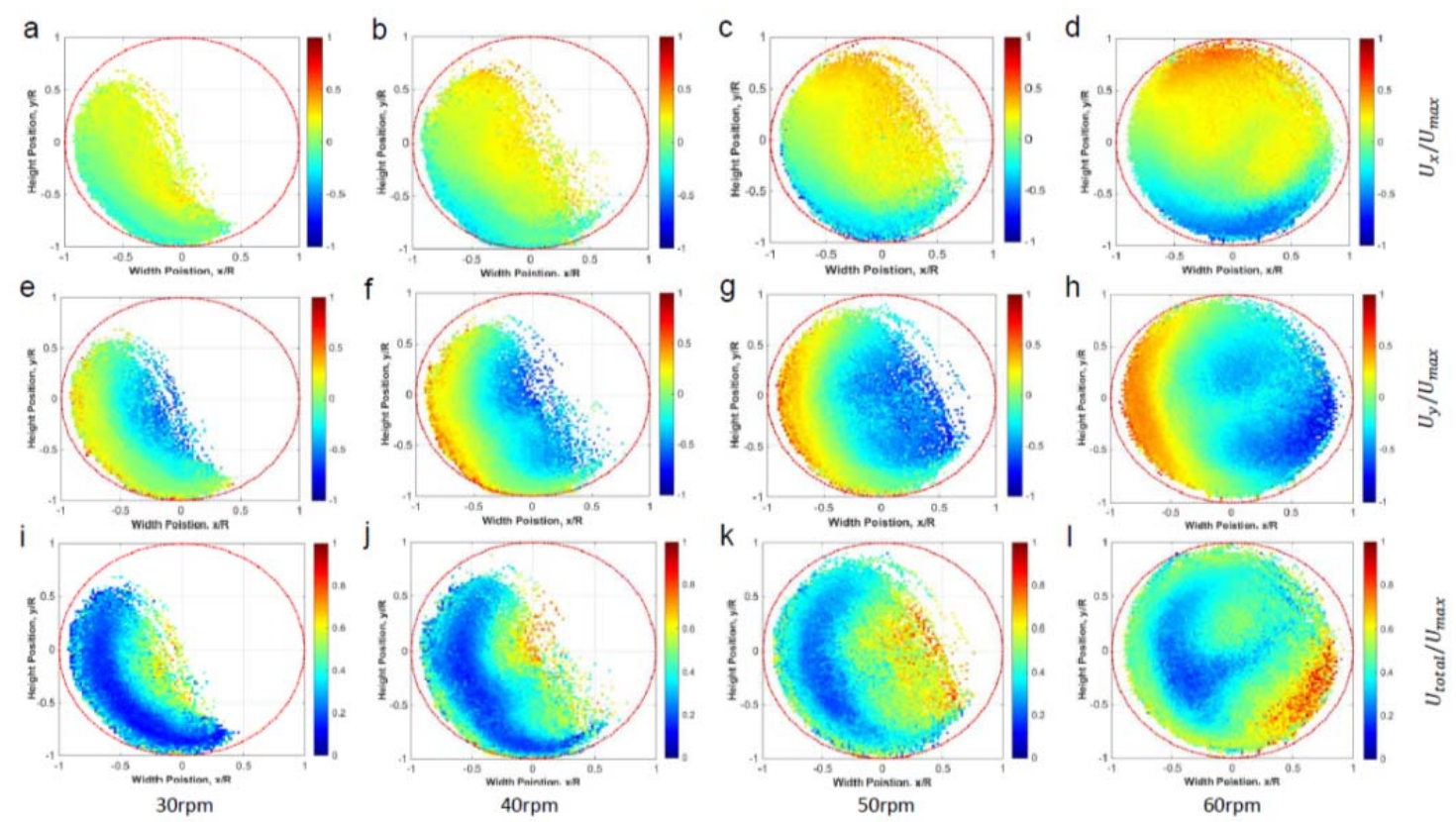

Figure 3. Eulerian velocity distribution of textile with different washing rotational speed ((a) (d) velocity distribution in $\mathrm{x}$ direction; (e) (h) velocity distribution in y direction; (i) (l) velocity distribution)

The estimated Eulerian velocities are all non-dimensional with reference to the maximum observed velocity, as shown in Figure 3 and Figure 5. The results show that the speed distribution greatly depends on drum rotational speed and water volume. It is clear that $U_{x}$ relies on the tangential velocity of the inner drum. For all rotational speeds and water volumes, the highest $U_{x}$ appears near the top and bottom of the drum, where the tangential velocity of the drum in the $\mathrm{x}$-direction is also the greatest, as descried in ${ }^{17}$. However, due to the falling motion of textiles, $U_{y}$ is at a maximum at the right-side drum wall where $U_{y}$ is greater than the velocity of inner drum.

The velocity couture plots of textile motion can be divided into two regions, a 'passive' region where textiles are lifted up by the drum wall and baffles, and an 'active' region where textiles fall freely under gravity. This has also been observed in canned product process ${ }^{38}$. The passive region is situated in the area close to the left-side drum wall where textiles follow the drum wall's rotation with a relatively slow speed as the drive force is mainly derived from the rotating drum. When the textiles are lifted to the top of the drum to achieve the dynamic repose angle (the slope at which the textiles will stabilize and come to rest when the inner drum rotating at a slow speed ${ }^{5,39,40}$ ), the dominant drag 
force changes from centrifugal force to gravity. The active region is formed when the textiles start falling under gravity and move faster than the rotating drum. Both rotational speed and water volume have significant impact on textile speed in the active region. The variation of textile speed in the active region may contribute to the agitation of the textile and water solution at the bottom of the drum, namely, the impact region, thus enhancing the convective mass transfer in textiles ${ }^{5}$. Overall, the high velocity impact of textiles at the bottom of front-load washer is likely to result in higher overall flow rates through the textile pores ${ }^{11}$.

From Fig.3, it could be seen that textile motion took an inverse 'D' shape during washing and the size of the inverse ' $\mathrm{D}$ ' shape increased with the rotational speed, until an ' $\mathrm{O}$ ' shape is formed at $60 \mathrm{rpm}$. The increased centrifugal force makes the textiles rotate with the inner drum, preventing them from free falling. However, when the rotational speed increased to 60rpm, the tangential velocity of the drum is about $1.76 \mathrm{~m} / \mathrm{s}$, which is almost equal to the critical centrifuging speed (at the top of the inner drum, centrifugal force is equal to gravity), resulting in textile rotating with the drum instead of falling under gravity. The estimated number of turnovers per min (number of turn over by the lifter ${ }^{41}$ per min) is shown in Figure 4. It is clear that the estimated turnovers increase with the rotating speed from 30rpm to 50rpm, but decrease at $60 \mathrm{rpm}$. The washing efficiency of carbon black stained strips follows the same trends. The carbon black soil is sensitive to rubbing action, while hydrodynamic flow action and flexing action have no significant effect on the removal of carbon black soil. ${ }^{22}$ As discussed above, textiles rotated with the drum when the rotational speed increased to 60rpm, resulting in less relative motion between textiles and decreasing rubbing action on carbon black soil.

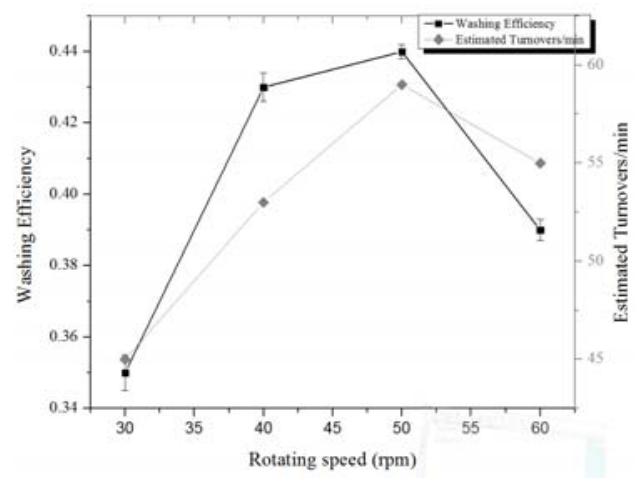

Figure 4. Washing efficiency and the estimated number of turnovers with different rotating speed 


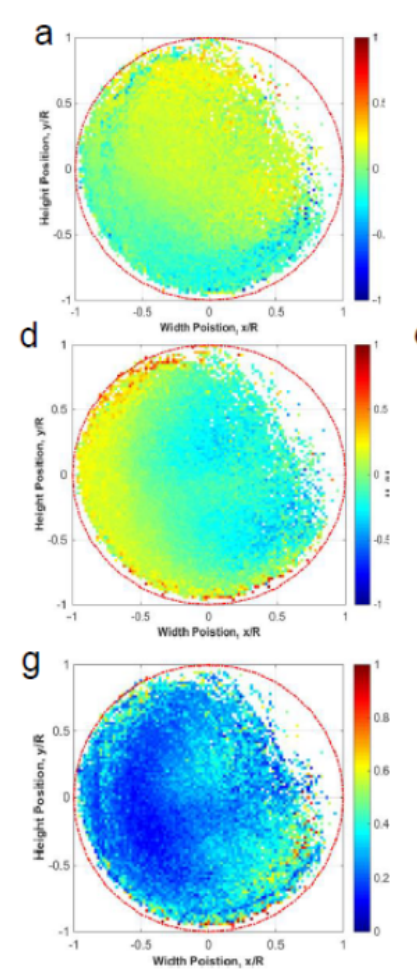

$6 \mathrm{~L}$
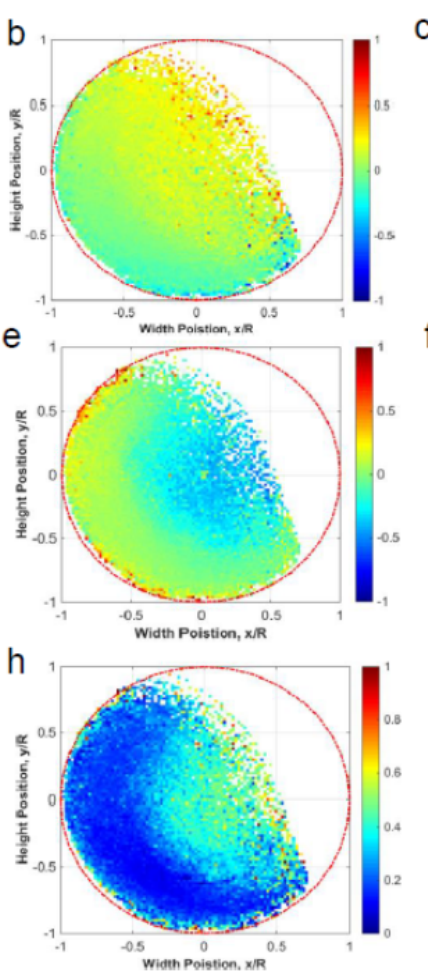

$9 \mathrm{~L}$
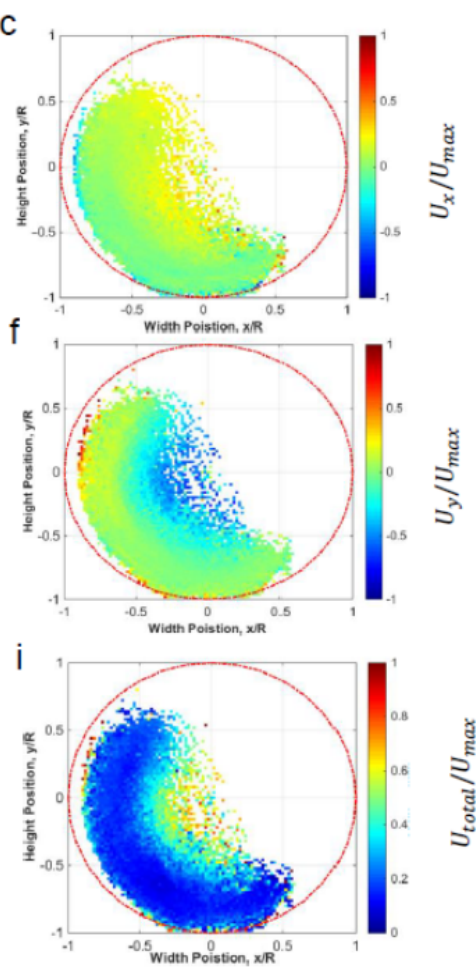

$12 \mathrm{~L}$

Figure 5 Eulerian velocity distribution of textile with different water volume ((a) (c) velocity distribution in $\mathrm{x}$ direction; (d) (f) velocity distribution in y direction; (g) (i) velocity distribution)

When water volume increases, the total motion region decreases because textile-fluid interaction force such as viscous drag force increase, thus limiting the motion of textiles. It seemed that water volume had more effect on $U_{y}$ than $U_{x}$ form Figure 5 (a) $\sim$ (c), particularly in active region. This is because that $U_{x}$ is dependent on tangential velocity of drum, while $U_{y}$ relies on textiles free fall motion. Too much water could restrict the lifting action of lifter on textiles due to the increase of buoyance force, thus affecting the height of that the textile could reach during rotation with the inner drum. The estimated turnovers per minute declined with the increasing water volume. However, the washing efficiency is least at 6 liter, with the value of $40 \%$ ( $47 \%$ for 9 liter and $44 \%$ for 12 liter). The soil removal is typically the synergistic effect between chemical and mechanical action. ${ }^{42}$ Surfactants can change the surface energy of water and soil, facilitating the penetration of water between textiles and adhered soil. ${ }^{43-45}$ The rinsing of stains is governed by water flow and mechanical action such as rubbing. ${ }^{6}$ Water mainly exists at the bottom of inner drum. Less water volume shortens the reaction time between soil and detergent, resulting in insufficient wetting and emulsification. This weakens the effect of water flow and mechanical action and thus leads to lower performance.

\subsubsection{Discussions}


Force analyses of textiles were carried out to explain qualitatively the difference in the textile motion for different rotational speeds and water volumes. In the drum system, the textile motion can be determined by Eq. (7) at the bottom of the drum and Eq. (8) at the top of the drum respectively, based on Newton's second law ${ }^{38,46}$.

$$
\begin{aligned}
& m_{i} \frac{d \overrightarrow{v_{l}}}{d t_{i}}=m_{i} \vec{g}+\overrightarrow{F_{f}}+\overrightarrow{F_{s}}+\sum \overrightarrow{F_{I}} \\
& m_{i} \frac{d V_{i}}{d t_{i}}=m_{i} \vec{g}+\overrightarrow{F_{s}}+\overrightarrow{F_{c}}+\sum \overrightarrow{F_{I}}
\end{aligned}
$$

Where $\vec{V}_{l}$ denotes the speed of textile centroid, $m_{i}$ denotes the wet textile mass, $\overrightarrow{F_{f}}$ denotes the textile-fluid interaction force which includes buoyancy and viscous drag, $\overrightarrow{F_{s}}$ denotes the normal force from inner drum and lifter, $\overrightarrow{F_{c}}$ denotes the centrifugal force provided by rotational drum, $\overrightarrow{F_{I}}$ is the textile-textile interaction force including friction force, compression force and shear force.

The movement of textiles is the result of the combined actions of all the forces. When textiles are out of water, there is no textile-liquid interaction. Textile rotation is maintained by the centrifugal force and friction force ${ }^{21}$. The centrifugal force increases with rotational speed, leading to greater height of the textiles. In addition, $U_{x}$ depends on the tangential velocity of drum, it increases with drum speed. These are the reasons why textile motion area gets larger with the increase of rotational speed. However, when the linear velocity of the drum approaches or exceeds the critical centrifugal velocity, it is possible for the textiles to rotate with the inner drum instead of free falling.

At the bottom of the drum, textiles motion is controlled by gravity, textile-fluid interaction force, and forces arising from the interaction and collisions between solids (textiles and drum wall). The flow of textile-liquid mixture is complex due to textile-fluid coupling and interactions between textiles. Textile-fluid interaction force changes with the water volume. In order to explain how water volume influences the textile motion, fabrics are simplified as the fabric plug with radius r, as shown in Fig.6. As textiles move, liquid surrounding the textile is moved by the textiles. This quantity of liquid that moves with the textile can be referred as added mass ${ }^{47,48}$. The added mass can be calculated as Eq. (9). Since the water in the washing machine is limited and the water displaced by the textiles is influenced by the water volume and textile volume. The added mass increases with water volume before the textiles totally immerse in water. This is due to the increase of displaced water by textiles. The added mass can be calculated as Eq. (9) and Eq. (10). The motion of fluid results in the lower speed of textiles and the kinetic energy of textile is dissipated into the surrounding fluid. The 
magnitude of the kinetic energy of fluid depends on added mass and can be calculated as Eq. (11). ${ }^{16}$ The increase of added mass increases the dissipated kinetic energy. In addition, the buoyance force also increases with water depth as the displaced water by textile increases. This decreases the contact between the textile and the lifter, weakening the lifting action of the lifter and lowering the maximum height that the textiles can reach. This might cause more sliding movement instead of free falling or tumbling.

$$
m_{\text {added }}=\alpha \times \rho_{f} V_{f}
$$

Where, $m_{t}$ is the mass of fabric plug, $m_{\text {added }}$ is the added mass, $\alpha$ is the added mass coefficient, $\rho_{f}$ is water density, $V_{f}$ is displaced water volume, which could be calculated by Eq. $(11)^{16}$. Once textiles immerse in water completely, the $V_{f}$ equals to $\left(\frac{2}{3}\right) \pi r^{3}{ }^{49}$

$$
\begin{gathered}
V_{f}=\pi h^{2}\left(\frac{r-h}{3}\right) \\
K_{\text {fluid }}=\frac{1}{2}\left(\frac{m_{\text {fabric }}}{m_{\text {fabric }}}\right) \times u_{1}{ }^{2}
\end{gathered}
$$

Where, $m_{\text {fabric }}$ is the mass of textile plug, $u_{1}$ is the velocity of textile impinging in water surface.

The textile motion is not only governed by gravity, buoyancy and drag, but also the interaction forces arising from collisions and compressions. These interactions between solids decrease with the water volume and vary with the textile location in the drum. The interaction forces and gravity are the dominating force for the textiles motion in the passive region. In this region, textiles pack together and move up at a lower speed. In active region, there is more space for textiles to cascade down, and the interactions between textiles are less significant than in the passive region, resulting in a greater textile speed.

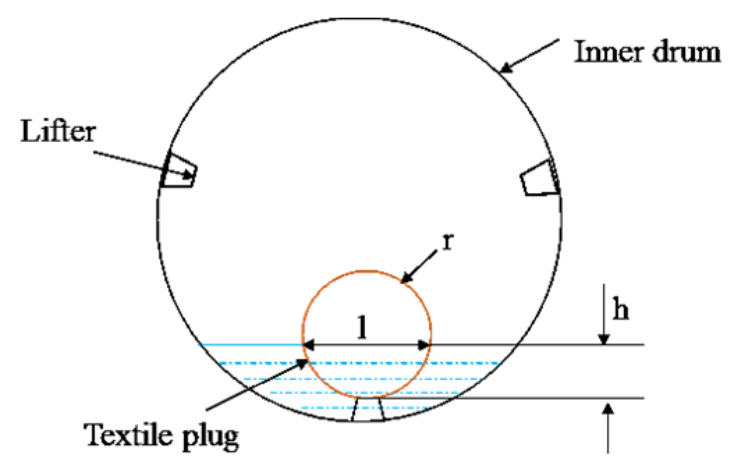

Figure 6. Impact of fabric plug 


\subsection{Effect of rotational speed and water volume on residence time}

The average time the tracer textiles stay in a particular region is defined as textile residence time. This time is a function of the total number of tracer passes in a specific region and, also a function of the velocity of the textile ${ }^{17,37}$. The contribution of textile motion to convective mass transfer in textiles can be qualitatively indicated by the residence time map. Figures 7 and 8 show the contour plots of the residence time for different rotational speeds and water volumes respectively. Regions with higher residence time are found adjacent to the left-side drum walls. Textiles seem to stay longer at lower heights of the drum. Comparing the residence time plots with the velocity plots, the longest residence time region corresponds to the passive region where the textiles are stactic or move very slowly . The textiles may slide in this region, leading to lower impact mechanical action. The magnitude of mechanical action can influence the size of the stagnant inter-fiber regions where transfer of water/soil only occur due to molecular diffusion, ${ }^{5,6}$ thus affecting the rate of flow thorough the textile. ${ }^{11}$ However, water is mainly at the bottom of the drum, thus the slower textile movement in the passive regions might prolong the contact time between stains and detergent, and enhance the interactions between detergents and soils.

The residence time for the tracer textile at the left bottom of the drum decreases as the rotational speed increases, as shown in Figure 7. However, the higher the water volume is, the longer residence time is at the left bottom of the drum, as shown in Figure 8. Textile motion is not only governed by gravity, buoyancy and viscous drag force, but also the interaction between the textiles and between textiles and drum wall. An increase of water volume means a decrease of textile fraction and an increase of drag force from water. The greater drag force from the liquid prevents the textiles from moving with the drum, leading to a longer residence time in the passive region.

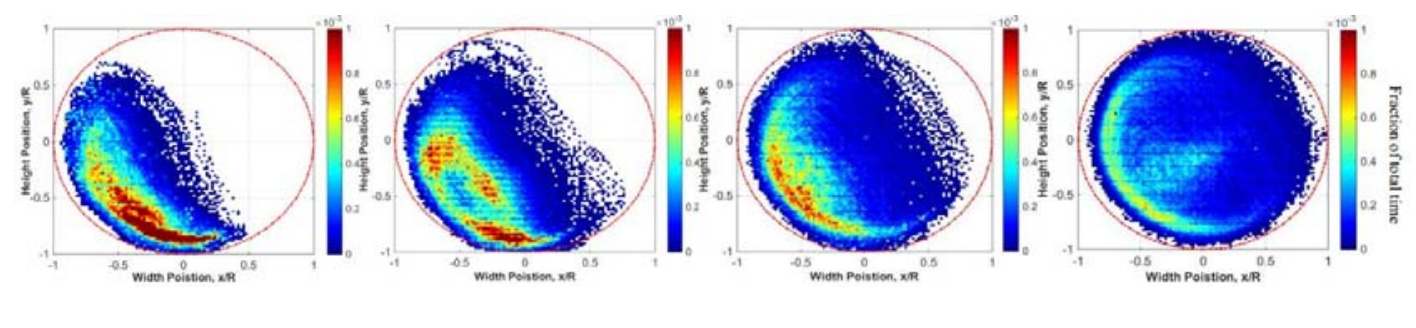

(a)

(b)

(c)

(d)

Figure 7. Residence time of textiles for different rotational speed ((a) 30rpm (b) 40rpm (c) 50rpm (d) 60rpm) 


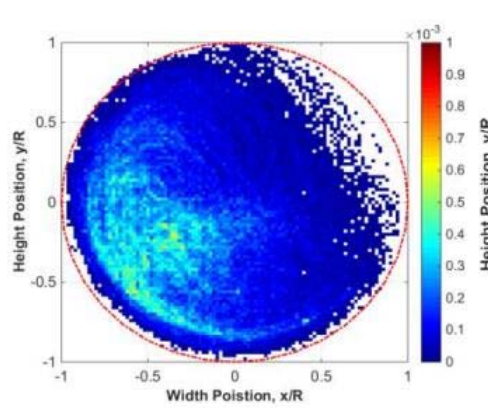

(a)

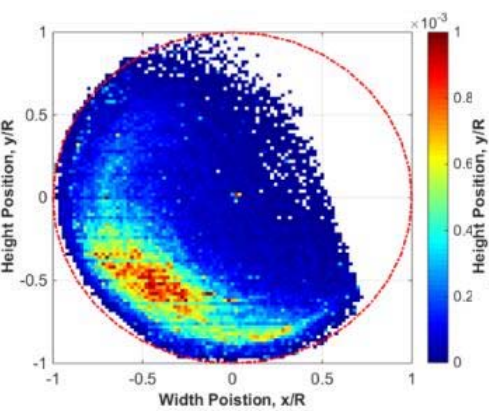

(b)

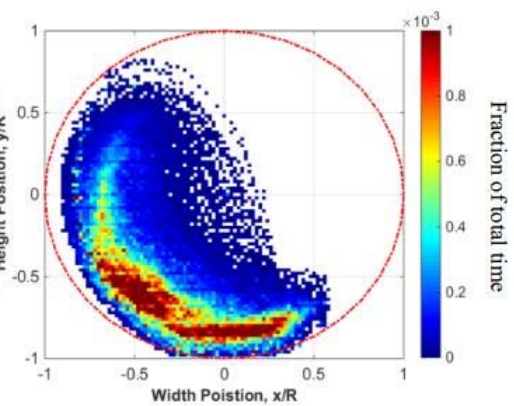

(c)

Figure 8. Residence time of textiles for different water volume ((a) 6L (b) 9L (c)12L)

\section{Conclusion}

Textile dynamics in a front loading washer can be characterized by the video system. The movement of textiles in a front loading washer is very complex and significantly depends on the rotational speed and water volume (textiles fraction). Textile motion takes a ' $\mathrm{D}$ ' shape at low or medium rotational speeds. And the size of the ' $\mathrm{D}$ ' shape increases with the rotational speed, but decreases with the water volume. The size of the motion area reflects, to a certain extent, the impact force of textiles on the liquid and drum during free fall. Appropriate rotational speed and water volume can lead to greater impact of textiles, forcing wash solution out of the textiles and, result in a higher washing performance due to higher flow rate through the textile structure.

There are two regions for velocity distribution, a 'passive' region where textiles are carried up by the drum wall and lifter, and an 'active' region where textiles fall freely. Both the drum rotational speed and the water volume have significant influences on the configuration of the two regions. The configuration of the two regions is likely to influence the soil removal for different stains due to different drag forces in these two regions. It is also found that the residence time distribution significantly varies with the rotational speed and water volume. The longest residence time region matches the passive region in velocity profile where textiles seem to be trapped or moved with a slightly low speed, which might decrease the impact action on textiles, resulting in slow flow rates in textiles. Information gathered in this work are being used to develop a mathematical model that describes the effect of different design parameters on washing efficiency and textile properties after washing to achieve a better washing process.

\section{Acknowledgements}


The authors would like to thank the National Natural Science Foundation of China for providing funding support to this research through project 71373041, and Donghua University for providing funding support to this research through project "the Fundamental Research Funds for the Central Universities", and this study is also supported by "the Fundamental Research Funds for the Central Universities "through project CUSF-DH-D-2017078 and Shanghai Science and Technology Committee for providing funding support to this research through project 17DZ2202900.

\section{Reference}

1. Bruce N, Hartline N, Karba S, Ruff B, Sonar S and Holden P. Microfiber Pollution and the Apparel Industry. University of California Santa Barbara, Bren School of Environmental Science \& Management

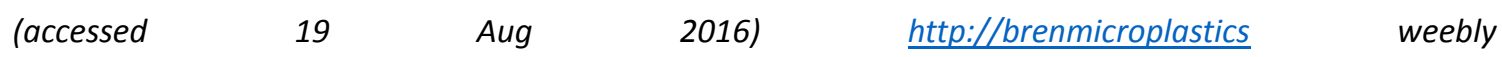
com/uploads/5/1/7/0/51702815/bren-patagonia_final_report pdf. 2016.

2. Peterson EC. Fabric Abrasion During Laundering. Textile Chemist \& Colorist. 1969; 1: 18-22.

3. Wei Y, Gong RH, Ning L and Ding X. Research on physical properties change and damage behavior of cotton fabrics dried in drum-dryer. The Journal of The Textile Institute. 2017: 1-12.

4. Grindstaff TH, Patterson HT and Billica HR. Studies of Soiling and Detergency. Textile Research Journal. 1970; 40: 35-42.

5. Van Den Brekel LDM. Hydrodynamics and mass transfer in domestic drum-type fabric washing machines. ICG-Printing Dordrecht, 1987.

6. Ganguli K and Van Eendenburg J. Mass transfer in a laboratory washing machine. Textile Research Journal. 1980; 50: 428-32.

7. Van der Donck J, So A and Frens G. The influence of stretching on salt release from porous yarns. Tenside, surfactants, detergents. 1998; 35: 119-22.

8. Tuzson J and Short BA. Mass transfer and the washing process. Textile Research Journal. 1960; 30: 983-9.

9. Van der Donck J. The influence of flow through textile layers on soil removal. Tenside, surfactants, detergents. 1999; 36: 222-4.

10. Campos LG and Hermes CJ. Experimental evaluation and transient simulation of detergent transport in household vertical axis washing machines. Chemical Engineering Research and Design. 2016; 109: 720-9.

11. Mac Namara C, Amador C and Bakalis S. The physics of washing machines. University of Birmingham, 2014.

12. Warmoeskerken $\mathrm{M}$, Van der Vlist $\mathrm{P}$, Moholkar $\mathrm{V}$ and Nierstrasz V. Laundry process intensification by ultrasound. Colloids and Surfaces A: Physicochemical and Engineering Aspects. 2002; 210: 277-85.

13. Janáčová $D$, Charvátová $H$, Kolomazník $K$, Vašek V, Mokrejš $P$ and Drga R. Computer simulation of washing processes. International Journal of Mathematical Models and Methods in Applied Sciences. 2011.

14. Akcabay DT. Physics Based Washing Machine Simulations. 2007.

15. Akcabay DT, Dowling DR and Schultz WW. Clothes washing simulations. Computers \& Fluids. 2014; 100: 79-94.

16. Ward D. Modelling of a horizontal-axis domestic washing machine. Journal of the Textile Institute. 
2000; 91: 207-34.

17. Mac Namara C, Gabriele A, Amador C and Bakalis S. Dynamics of textile motion in a front-loading domestic washing machine. Chemical Engineering Science. 2012; 75: 14-27.

18. Park $\mathrm{J}$ and Wassgren $\mathrm{C}$. Modeling the dynamics of fabric in a rotating horizontal drum using the discrete element method. Particulate Science and technology. 2003; 21: 157-75.

19. Park J. Modeling the dynamics of fabric in a rotating horizontal drum. 2003.

20. Balt A, van den Brekel L, Vandecasteele $C$ and Kolar Z. Radiotracer study of wash load movement in a drum-type fabric washing machine using a gamma camera. International Journal of Radiation Applications and Instrumentation Part A Applied Radiation and Isotopes. 1987; 38: 7-12.

21. Yun $\mathrm{C}$ and Park $\mathrm{CH}$. The effect of fabric movement on washing performance in a front-loading washer II: under various physical washing conditions. Textile Research Journal. 2014: 0040517514545260.

22. Lee A, Seo MH, Yang S, Koh J and Kim H. The effects of mechanical actions on washing efficiency. Fibers and Polymers. 2008; 9: 101-6.

23. Park S, Yun C, Kim J and Park CH. The effects of the fabric properties on fabric movement and the prediction of the fabric movements in a front-loading washer. Textile Research Journal. 2013: 0040517512468810.

24. Yun $\mathrm{C}$, Park $\mathrm{S}$ and Park $\mathrm{CH}$. The effect of fabric movement on washing performance in a front-loading washer. Textile Research Journal. 2013: 0040517512452927.

25. Yun $\mathrm{C}$ and Park $\mathrm{CH}$. The effect of fabric movement on washing performance in a front-loading washer III: Focus on the optimized movement algorithm. Textile Research Journal. 2015: 0040517515590417.

26. Quaynor L, Takahashi M and Nakajima M. Effects of laundering on the surface properties and dimensional stability of plain knitted fabrics. Textile Research Journal. 2000; 70: 28-35.

27. Higgins $L$, Anand $S$, Holmes $D$, Hall $M$ and Underly K. Effects of various home laundering practices on the dimensional stability, wrinkling, and other properties of plain woven cotton fabrics: Part II: Effect of rinse cycle softener and drying method and of tumble sheet softener and tumble drying time. Textile Research Journal. 2003; 73: 407-20.

28. Van Amber RR, Niven BE and Wilson CA. Effects of laundering and water temperature on the properties of silk and silk-blend knitted fabrics. Textile Research Journal. 2010; 80: 1557-68.

29. Liu H, Wang Y, Gong RH, Zeng J and Ding X. The relationships between washing parameters, fabric movement, and wrinkling in a top-loading washer. Textile Research Journal. 2017: 0040517517700197.

30. Park S, Yun C, Kim J and Park CH. The effects of the fabric properties on fabric movement and the prediction of the fabric movements in a front-loading washer. Textile Research Journal. 2013; 83: 1201-12.

31. Yun $\mathrm{C}$, Park $\mathrm{S}$ and Park $\mathrm{CH}$. The effect of fabric movement on washing performance in a front-loading washer. Textile Research Journal. 2013; 83: 1786-95.

32. Yun $\mathrm{C}$ and Park $\mathrm{CH}$. The effect of fabric movement on washing performance in a front-loading washer II: under various physical washing conditions. Textile Research Journal. 2015; 85: 251-61.

33. Paclík P, Novovičová J, Pudil P and Somol P. Road sign classification using Laplace kernel classifier. Pattern Recognition Letters. 2000; 21: 1165-73.

34. Ren F, Huang J, Jiang R and Klette R. General traffic sign recognition by feature matching. Image and Vision Computing New Zealand, 2009 IVCNZ'09 24th International Conference. IEEE, 2009, p. 409-14.

35. Kilian J. Simple image analysis by moments. OpenCV library documentation. 2001.

36. Bakalis $\mathrm{S}$, Fryer $\mathrm{P}$ and Parker $\mathrm{D}$. Measuring velocity distributions of viscous fluids using positron emission particle tracking (PEPT). AIChE journal. 2004; 50: 1606-13. 
37. Pérez-Mohedano R, Letzelter N, Amador C, VanderRoest C and Bakalis S. Positron Emission Particle Tracking (PEPT) for the analysis of water motion in a domestic dishwasher. Chemical Engineering Journal. 2015; 259: 724-36.

38. Yang Z, Fan X, Bakalis S, Parker D and Fryer P. Impact of solids fraction and fluid viscosity on solids flow in rotating cans. Food research international. 2008; 41: 658-66.

39. Atwood-Stone $\mathrm{C}$ and McEwen A. Measuring Dynamic Angle of Repose in Low Gravity Environments Using Martian Sand Dunes. Lunar and Planetary Science Conference. 2013, p. 1727.

40. Dubé O, Alizadeh E, Chaouki J and Bertrand F. Dynamics of non-spherical particles in a rotating drum. Chemical Engineering Science. 2013; 101: 486-502.

41. Yun $\mathrm{C}$ and Park $\mathrm{CH}$. The effect of fabric movement on washing performance in a front-loading washer III: Focus on the optimized movement algorithm. Textile Research Journal. 2016; 86: 563-72.

42. Woo JH, Kim J and Park $\mathrm{CH}$. Contributing ratio of the mechanical and the physicochemical actions to washing efficiency of mineral oil and protein soils. Fibers and Polymers. 2014; 15: 645-52.

43. Kim S. Science of detergent and washing. Kyomoon, Seoul. 2008.

44. Rosen MJ and Kunjappu JT. Surfactants and interfacial phenomena. John Wiley \& Sons, 2012.

45. Han HR, Chung SE, Kim J and Park CH. Mechanical and physicochemical contribution in removal of different soil types on cotton fabric. Textile Research Journal. 2015; 85: 2009-19.

46. Duchanoy $\mathrm{C}$ and Jongen TR. Efficient simulation of liquid-solid flows with high solids fraction in complex geometries. Computers \& fluids. 2003; 32: 1453-71.

47. Brennen C. A Review of Added Mass and Fluid Inertial Forces. BRENNEN (CE) SIERRA MADRE CA, 1982.

48. Koo W and Kim J-D. Simplified formulas of heave added mass coefficients at high frequency for various two-dimensional bodies in a finite water depth. International Journal of Naval Architecture and Ocean Engineering. 2015; 7: 115-27.

49. Moody FJ. Introduction to unsteady thermofluid mechanics. New York, Wiley-Interscience, 1990, 667 p. 1990. 